\title{
David Oliver: Keeping care home residents out of hospital
}

Few doctors working in acute medicine get through an on-take shift without seeing patients brought by ambulance from care homes. If it's distressing for us to witness, it's much more so for them. Sometimes a short hospital visit may be in a care home resident's interests, but often it's not. A recent systematic review showed common avoidable harms associated with residents' hospitalisation. ${ }^{1}$ A deeper analysis of hospital admissions in Ireland $^{2}$ showed little added value for many residents.

The United Kingdom has about 20000 nursing and residential homes (or "aged care facilities") and 430000 residents, almost all of whom have age related disability, frailty, multimorbidity, or cognitive impairment. ${ }^{3}$ Median life expectancy in nursing homes is 15 months, one in four residents dying within the first year, so planning and support for end of life care should be the norm. ${ }^{45}$

One third of residents admitted acutely to hospital die during that admission, ${ }^{1}$ and it's often apparent when they first arrive that they are close to the end of life-so why not support them to die in the place they live? Many more, on arrival at hospital, receive only very short term treatment with fluids, oxygen or antibiotics, or $\mathrm{x}$ rays to exclude injury, but they then risk being marooned in hospital, waiting to return. ${ }^{6}$

Yet care home residents aged over 75 are three times more likely to be admitted as emergencies than over $75 \mathrm{~s}$ in the general population. $^{?}$

Professional consensus ${ }^{7}$ and NICE guidelines ${ }^{8}$ have both emphasised that care homes need proactive care planning and equitable access to medical and other healthcare inputs. These should include palliative care and support for dementia and other mental health problems: with 24 hour care available, such residences should allow for rapid "hospital at home"-style interventions in a crisis, or collaboration with ambulance staff and emergency GPs to make conveyance a last resort. Specialist clinicians such as geriatricians or specialist nurse practitioners can work with care homes to support them. ${ }^{9}$

It's not all about external input from the health services. Care home staff — already undervalued and scarce — need to feel trained, supported, and empowered (by regulators, managers, and primary care teams) to do the right thing for residents rather than feel obliged to use acute admission as the default option. ${ }^{10}{ }^{11}$ And residents' families need honest conversations about the nature of frailty, end stage dementia, and "progressive dwindling."

Done well and systematically, these things can achieve drastic reductions in ambulance conveyance or hospital admission, as recent cases in Ashford ${ }^{12}$ and Walsall ${ }^{13}$ have shown. NHS England is now supporting "vanguard" sites for care home medicine. It's surely time such approaches were mainstream.

Competing interests: I have read and understood the BMJ policy on declaration of interests and have no relevant interests to declare.

Provenance and peer review: Commissioned; not externally peer reviewed.

1 Dwyer R, Gabbe B, Stoelwinder JU, Lowthian J. A systematic review of outcomes following emergency transfer to hospital for residents of aged care facilities. Age Ageing 2014;43:759-66. http://ageing.oxfordjournals.org/content/early/2014/10/09/ageing.afu117. full.

2 Delos Reyes J, O'Keefe J, Cooney MT, O'Shea D, Hughes G, O'Callaghan S. Multiple hospital admissions do not improve older nursing home residents' survival: a trigger for advance care planning. Presentation to British Geriatrics Society scientific meeting. May 2015. www.bgs.org.uk/pdf_cms/admin_archive/2015_spring_abstracts.pdf (p56).

3 Oliver D. Enhancing healthcare in care homes: integration in practice (blog). King's Fund. 19 May 2015. www.kingsfund.org.uk/blog/2015/05/enhancing-health-care-care-homesintegration-practice.

4 British Geriatrics Society. Quest for quality: an inquiry into the quality of healthcare support for older people in care homes: a call for leadership, partnership and improvement. Jun 2011. www.bgs.org.uk/campaigns/carehomes/quest_quality_care_homes.pdf.

5 Badger $\mathrm{F}$, Thomas $\mathrm{K}$, Clifford $\mathrm{C}$. Raising standards for elderly people dying in care homes. Eur J Palliat Care 2007;14:238-41. http://bit.ly/1UIOFVA.

6 Connolly W, Butt $\mathrm{H}, \mathrm{McC}$ arthy $\mathrm{C}$. Why are nursing home patients requiring inpatient hospital care? Presentation to British Geriatrics Society scientific meeting. May 2015. www.bgs.org.uk/pdf_cms/admin_archive/2015_spring_abstracts.pdf (p53).

7 Smith P, Sherlaw-Johnson C, Ariti C, Bardsley M; QualityWatch. Focus on: admissions from care homes. Nuffield Trust and Health Foundation 2015. www.health.org.uk/sites/ default/files/QualityWatch FocusOnHospitalAdmissionsFromCareHomes.pdf.

8 National Institute for Health and Care Excellence. Older people with social care needs and multiple long term conditions. Guideline NG22. 4 Nov 2015. www.nice.org.uk/guidance/ ng22/resources/older-people-with-social-care-needs-and-multiple-longterm-conditions1837328537797

9 British Geriatrics Society. Commissioning guidance: high quality health care for older care home residents. 2013. www.bgs.org.uk/campaigns/2013commissioning/Commissioning 2013.pdf.

10 Gordon AL. What is the case for care home medicine? The geriatrician's perspective. J R Coll Physicians Edinb 2015;45:148-53. www.rcpe.ac.uk/sites/default/files/gordon.pdf. 1 My Home Life. Good practice. http://myhomelife.org.uk/good-practice/.

12 Lisk R. Hospital admissions from care homes. British Geriatrics Society blog. 13 Mar 2015.

britishgeriatricssociety.wordpress.com/2015/03/13/hospital-admissions-from-care-homes/.

13 Roberts S. Reducing hospital admissions: a new integrated model for care homes. British Geriatrics Society blog. 29 Jul 2015.

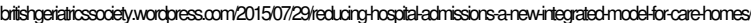

Cite this as: BMJ 2016;352:1458

๑ BMJ Publishing Group Ltd 2016 
